Document downloaded from:

http://hdl.handle.net/10251/50093

This paper must be cited as:

Igual Muñoz, AN.; Espallargas Älvarez, N.; Johnsen, R.; Torres, C. (2013). A new experimental technique for quantifying the galvanic coupling effects on stainless steel during tribocorrosion under equilibrium conditions. Wear. 307(1-2):190-197. doi:10.1016/j.wear.2013.08.026.

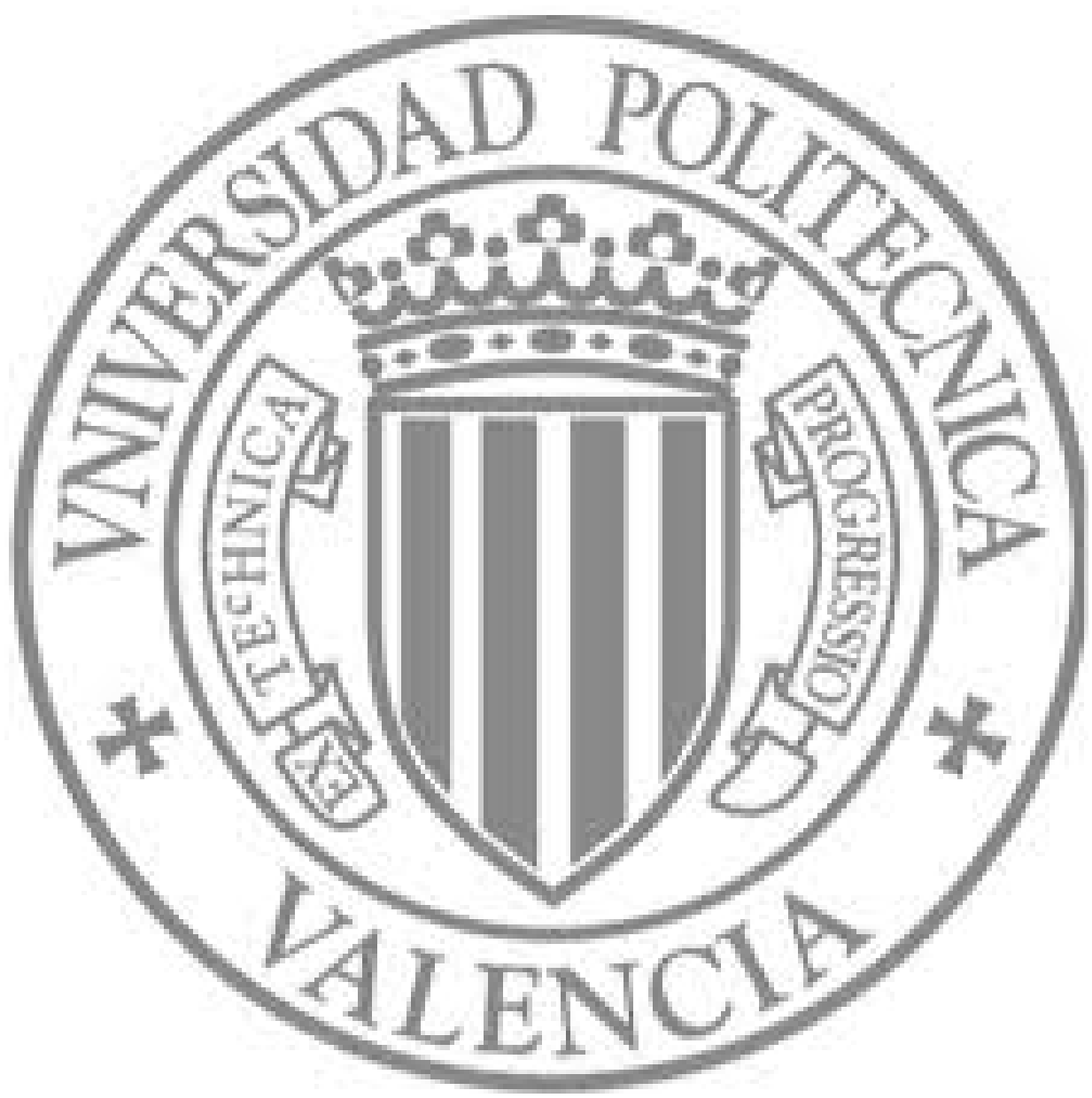

The final publication is available at

http://dx.doi.org/10.1016/j.wear.2013.08.026

Copyright Elsevier 


\section{Elsevier Editorial System(tm) for Wear Manuscript Draft}

\section{Manuscript Number: IH-8390R1}

Title: A new experimental technique for quantifying the galvanic coupling effects on stainless steel during tribocorrosion under equilibrium conditions

Article Type: Full-Length Article

Keywords: tribocorrosion, galvanic coupling, wear accelerated corrosion, Zero-Resistance Ammeter (ZRA)

Corresponding Author: Prof. Nuria Espallargas,

Corresponding Author's Institution: Norwegian University of Science and Technology (NTNU)

First Author: Nuria Espallargas

Order of Authors: Nuria Espallargas; Roy Johnsen; Cristian Torres; Anna Igual-Muñoz

Abstract: Galvanic coupling during tribocorrosion of passive metals at open circuit potential (OCP) generates a wear accelerated corrosion process within the depassivated area (worn surface) that is electrically in contact with the still passive one. The galvanic coupling effect at OCP was recently modelled using an electrochemical approach allowing for the theoretical quantification of the wearaccelerated corrosion under equilibrium conditions. Despite the usefulness of this model that mathematically determines the electrochemical conditions inside the wear track in terms of anode potential via the approximation of the net anodic current density, an experimental technique allowing for their experimental determination is essential in the effort to verify the galvanic coupling models and further understand the tribocorrosion mechanisms at OCP. In the present work, a new experimental technique based on galvanic current and potential measurements through a ZeroResistance Ammeter (ZRA) for quantifying the electrode potential and anodic current inside the wear track during rubbing at OCP has been assessed. This experimental set-up has allowed for the first time to determine the prevailing electrochemical conditions (electrode potential and anodic current) inside the wear track by solely exposing the wear track to the electrolyte and physically separating the cathode from the anode (wear track). The effects of sliding wear at open circuit potential have been investigated for a super duplex stainless steel (UNS S32750) in $3.4 \mathrm{wt} . \% \mathrm{NaCl}$. The new experimental set-up proposed in this work, separates the cathode from the anode and exposes solely the wear track to the electrolyte. Using well-established electrochemical theories, the effect of the extent of the galvanic coupling on wear at the open circuit potential conditions has been quantified. 


\section{WEAR}

\section{Confirmation of Authorship}

\section{Please save a copy of this MS Word file, complete and upload as the "Confirmation of Authorship" file.}

As corresponding author, I Nuria Espallargas hereby confirm on behalf of all authors that:

1) The authors have obtained the necessary authority for publication.

2) The paper has not been published previously, that it is not under consideration for publication elsewhere, and that if accepted it will not be published elsewhere in the same form, in English or in any other language, without the written consent of the publisher.

3) The paper does not contain material which has been published previously, by the current authors or by others, of which the source is not explicitly cited in the paper.

Upon acceptance of an article by the journal, the author(s) will be asked to transfer the copyright of the article to the publisher. This transfer will ensure the widest possible dissemination of information. 
Dear Editor,

This paper was written for inclusion in your journal, Wear.

This manuscript deals with the development of a new experimental technique to measure wear-accelerated corrosion during tribocorrosion at open circuit potential. The technique consists of a modification of a conventional triboelectrochemistry set-up and the use of a zero-resistance ammeter. This is the first paper, as far as we know, that deals with this topic in a successful way. The tool developed here will be of usefulness for the tribocorrosion community and represents a step forward in the field.

We hope this paper can be considered for publication in Wear.

Best regards,

The authors. 


\section{Suggested reviewers}

Dr. Stefano Mischler

EPFL, Switzerland

e-mail: stefano.mischler@epfl.ch

Prof. Robert J.K. Wood

Southampton University, UK

e-mail: r.wood@soton.ac.uk

Assitant Prof. Marwan Azzi

Notre Dame University, Lebanon

e-mail: mazzi@ndu.edu.lb 


\section{Highlights}

- A new experimental tool for determining wear-accelerated corrosion at open circuit potential (equilibrium conditions).

- Analysis of the galvanic coupling mechanism in tribocorrosion.

- Quantitative determination of the galvanic coupling parameters in tribocorrosion in equilibrium conditions.

- The use of the zero-resistance ammeter (ZRA) technique in tribocorrosion.

- The physical separation of the anode (worn area) and the cathode (unworn area) by for determining the galvanic potential and anodic current. 


\section{ANSWERS TO REVIEWERS}

\section{The changes in the new version of the article are highlighted in yellow.}

Please also note that some of the modelling part has been removed after a discussion with all authors. We have only kept the classical documented modelling (see reference 11) in the galvanic coupling situation. All the geometrical part has been considered not relevant for this paper and therefore has been removed.

We think that giving more emphasis to the experimental part will only improve the quality of the paper since the main achievement of this work is actually the experimental technique.

\section{Comments from Reviewer \#1:}

1. Sample preparation: need more details on the epoxy coating. How thick it is? How does the thickness maintain during the preparation and with different tests. Possibly an electrochemical impedance spectroscopy (EIS) before each test might provide an idea how stable is the film. Authors need to comment on it.

Answer: thank you for the comment. We have included the information about the coating thickness in the text (see section 2.3.1). In addition and as also requested by reviewer \#2, we have included a new figure (now new Figure 5) showing the isolating properties of the coating right before testing. We have performed a polarization curve on the epoxy coating and also we have measured the OCP of the epoxy coated samples over time. Since as expected the polarization curve did not provide with any information due to the isolating properties, we only show in the paper the potential recorded, which we consider is much easier to understand.

In addition, a new polarization curve of the un-coated sample (Figure 4) has been added.

2. The effect of uncovered sample (separately placed) might not represent the real unworn area in a tribocorrosion experiment. In a usual tribocorrosion experiments, the unworn area also under mechanical loading (might not be in tribological contact). Possibly, this is an limitation of the this study. (please include in the manuscript)

Answer: we agree with the reviewer and have added this comment now in the manuscript, see section 2.4 .

3. From the manuscript, it is not clear, how the initial contact occurs during the sliding stage. What is the effect of epoxy particles/debris on the electrochemical response as well as frictional behavior. Further, the role of wear particle from the metal specimen should be included.

Answer: the initial contact during sliding occurs in the same way as in a conventional tribocorrosion test. The effect of the epoxy wear particles on friction and electrochemical response has not been analysed. The reason for the second one is that we don't expect a large influence of the epoxy particles in the electrochemical response since they are non-electrically conductive. In the case of the metal wear particles we have now included a new discussion in section 3.3 also according to the comments made by reviewer \#2.

4. During the sliding, there is a high chance that the cracks can be generated in the epoxy layer. Does this effects are considered during the test or in the discussion?

Answer: No cracking of the epoxy coating was observed during the tests. This coating is very plastic and no brittleness in this electrolyte was observed. Actually in parallel tests performed 
in $\mathrm{H} 2 \mathrm{SO} 4$ a brittle behaviour of the coating was observed, therefore those results had to be discarded due to the bad performance of the coating.

5. There is also some confusion exist on the term " wear-accelerated corrosion". It is well know that during the tribcorrosion, the governing mechanisms are the result of the interactions between wear and corrosion. As wear-accelerated corrosion exist, there is also corrosion-accelerated wear exist, at one time point. Possibly, one is dominating, and other is negligible, however, it is cannot be avoided completely (due to the dynamic nature). Hence I would suggest, authors should re-consider by giving emphasis on wear-accelerated corrosion, possibly discussed detail in the manuscript.

Answer: we agree with the reviewer on this point. We have actually neglected the corrosionaccelerated wear part since it's contribution in this process in minimal. Actually in other publications by us and other authors (e.g. Mischler) the corrosion-accelerated wear term in sliding tribocorrosion conditions has been documented to be minimal.

6. The reported finding are based on one potential OCP, where the passivation behaviour is observed in miniscale. Wear-accelerated corrosion possibly higher at passive region. Authors needs to comment on it.

Answer: yes, larger wear-accelerated corrosion is expected to occur at higher passive region. A comment (together with a new reference [6]) has been added in the manuscript. See Introduction.

7. The proposed model is interesting. Used solution is $\mathrm{NaCl}$. What is the effect of solution chemistry, (biological solution) on this model? Or any comments?

We actually don't have the answer for this, but in reference 11 you can see the same model applied in 2 different solutions where it fits well in both cases. However, please note that we have minimized the model contribution in the paper to give more emphasis to the experimental part. This has been decided since the model has been published and extensively explained in other references such as reference 11 (used in this paper). We hope this small change can be accepted by the reviewers.

Comments from Reviewer \#2:

This is a very interesting article, it explores a new method for measuring tribocorrosion of materials at the open circuit potential without imposing artificial condition like anodic and cathodic polarization. Below are few points that I would like the authors to explain/clarify:

(a) It is recommended to include in Figure 4 the polarization curve of the coated sample (without sliding) to assess the protective efficiency of the coating.

Answer: this has been taken into account as also appointed by reviewer \#1.

(b) Using the author's setup for tribocorrosion, how one can make sure that all current generated in the wear track circulated through the ZRA system and got measured. Why did the authors eliminate the possibility of having some cathodic reactions in the wear track?

Answer: We completely agree with the reviewer comment with respect to the possibility of having secondary cathodic reactions in the anode that may affect the measured current generated in the wear track. In neutral solutions, the reduction of water and/or oxygen is the dominating cathodic reaction, which may occur in principle also on the anodes. However, this 
contribution is neglected here because in the present experiments the worn area is much smaller than the cathode surface area.

(c) At $10 \mathrm{~N}$, the authors observed a trend toward more positive potentials in the OCP response and a downtrend in the anodic current. Can the authors explain this behavior?

Answer: this has been addressed now in the reviewed version, see new text in section 3.3.

(d) In the text, the authors used "wear-accelerated corrosion" and "wear accelerated corrosion", authors should be consistent and use only one form of the term.

Same for "cathode potential" and "cathodic potential".

Answer: this has been now modified in the text. 


\title{
A new experimental technique for quantifying the galvanic coupling effects on stainless steel during tribocorrosion under equilibrium conditions
}

\author{
N. Espallargas ${ }^{1, *}$, R. Johnsen ${ }^{1}$, C. Torres ${ }^{1}$, A.I. Muñoz ${ }^{2}$ \\ ${ }^{1}$ NTNU, Faculty of Engineering Science and Technology, Dept. Engineering Design and Materials. Tribology Lab, N- \\ 7491 Trondheim, Norway. \\ ${ }^{2}$ UPV, Department of Chemical and Nuclear Engineering, camino de vera s.n., 46022 Valencia, Spain. \\ * Corresponding author. Tel.: +47 46917452; fax: +47 73594129. \\ E-mail address: nuria.espallargas@ntnu.no (Nuria Espallargas)
}

\begin{abstract}
Galvanic coupling during tribocorrosion of passive metals at open circuit potential (OCP) generates a wear-accelerated corrosion process within the depassivated area (worn surface) that is electrically in contact with the still passive one. The galvanic coupling effect at OCP was recently modelled using an electrochemical approach allowing for the theoretical quantification of the wear-accelerated corrosion under equilibrium conditions. Despite the usefulness of this model that mathematically determines the electrochemical conditions inside the wear track in terms of anode potential via the approximation of the net anodic current density, an experimental technique allowing for their experimental determination is essential in the effort to verify the galvanic coupling models and further understand the tribocorrosion mechanisms at OCP. In the present work, a new experimental technique based on galvanic current and potential measurements through a Zero-Resistance Ammeter (ZRA) for quantifying the electrode potential and anodic current inside the wear track during rubbing at OCP has been assessed. This experimental set-up has allowed for the first time to determine the prevailing electrochemical conditions (electrode potential and anodic current) inside the wear track by solely exposing the wear track to the electrolyte and physically separating the cathode from the anode (wear track). The effects of sliding wear at open circuit potential have been investigated for a super duplex stainless steel (UNS S32750) in 3.4 wt.\% NaCl. The new experimental set-up proposed in this work, separates the cathode from the anode and exposes solely the wear track to the electrolyte. Using well-established electrochemical theories, the effect of the extent of the galvanic coupling on wear at the open circuit potential conditions has been quantified.
\end{abstract}

Keywords: tribocorrosion, galvanic coupling, wear-accelerated corrosion, Zero-Resistance Ammeter (ZRA). 


\section{Introduction}

Passive metals, such as stainless steels, get protected against corrosion by a dense oxide film of a few nanometers thickness on the surface [1]. Engineering passive materials (e.g. stainless steels, $\mathrm{Ti}$ alloys and $\mathrm{NiCr}$ alloys) are crucial in many applications since they keep passive in a wide range of electrolytes under equilibrium conditions. These equilibrium conditions can be described by the open circuit potential (OCP), which is the potential established spontaneously between the material and the electrolyte without any external current. At this potential both the cathodic and anodic reactions are in equilibrium and take place simultaneously at the same rate setting the total net current to zero [1].

These materials are usually employed in corrosive environments and their corrosion resistance is thus an important parameter in their satisfactory operation. However, there are several applications such as for example biomedical implants [2] and hydraulic cylinders [3] where mechanical loading can act simultaneously to corrosion, thus contributing to degradation. This degradation process is known as tribocorrosion and its extent depends on the prevailing electrochemical conditions $[4,5]$. When these passive materials are subjected to sliding under equilibrium conditions (open circuit potential), worn active areas are formed where the passive layer is removed leaving the unworn areas passive. In this tribocorrosion situation the equilibrium potential changes and may cause wear-accelerated corrosion in the worn regions [4]. Although the largest wear-accelerated corrosion is expected to occur in the passive domain, it has also been documented a non-negligible contribution of this mechanism during tribocorrosion of passive alloys at the equilibrium conditions [6].

In laboratory conditions it is possible to simulate the tribocorrosion process by rubbing a passive metal against an inert counterpart $[4,5]$ while simultaneously measuring electrochemical parameters such as the potential evolution. In this case tribocorrosion testing at open circuit potential (OCP) of passive metals results in a cathodic shift of potential from the initial OCP to lower values. The cathodic shift results from the galvanic coupling established between the active worn area and the passive unworn area, which is much larger in area than the worn/rubbed region [5]. In the literature, OCP during tribocorrosion is mainly measured over the whole surface and consists of a mixed potential established between the worn and unworn areas [4, 7-11]. Therefore, the measured potential is a mixed potential between these areas, as known from the mixed potential theory [8]. The measured potential will be altered according to modifications in active-to-passive (anode-to-cathode) surface area ratios and anodic and cathodic polarization properties, among others. This situation makes it difficult to evaluate the corrosion kinetics of the process and to further study the mechanisms contributing to wear.

Experimentally, the electrochemical data that can be extracted from a tribocorrosion test at OCP is only the potential drop. As mentioned above, at OCP the electrolyte-material system is in equilibrium therefore the total net current flowing is zero and cannot be measured. This makes it difficult to quantify the wear-accelerated corrosion expected in this galvanic coupling situation. However, the wear track is in an active state and thus suffers from increased anodic dissolution kinetics [1-5]. In addition, it is essential to know the potential in the worn areas in order to quantify the wear-accelerated corrosion under equilibrium situations. Several attempts to quantify the galvanic coupling in tribocorrosion OCP tests have been reported in the literature [12-17]. In some cases, zero resistance ammeters (ZRA) were used for measuring the galvanic potential and the current flowing between the worn and unworn areas of an electrode. Some setups [14, 16-18] consisted of a working electrode sample (rubbed at OCP), a microelectrode acting as the cathode 
and a reference electrode. Despite the use of a ZRA to measure the galvanic current generated in the system it does not correspond to the anodic current within the wear track because of the lack of the size of the counter electrodes, which generates an unbalanced area ratio between the anode and the counter microelectrode. The latter makes the detection of the galvanic current much lower than the generated one. On the other hand, in those experimental setups where the counter electrode was the same passive material as the sample tested $[12,13]$, the consumption of electrons by the cathodic reactions became a limitation for quantification. In all these cases the potential inside the worn area still remains unknown.

More recently a theoretical model for predicting the cathodic potential during rubbing at OCP was proposed [11]. This model uses the mixed potential theory used in corrosion [1, 8] for determining the cathodic potential outside the wear track. However in this model an essential parameter like the anodic current density is arbitrary chosen in order to determine the potential within the wear track.

In a work performed at NTNU in 2009 [15] an experimental set-up for measuring the potential exclusively inside the worn area of a passive material was successfully designed by isolating the anode area in a tribocorrosion test at OCP. In this work, an epoxy coating was used to cover a stainless steel sample prior to rubbing using an alumina ball. Upon rubbing, the wear track generated exposed solely the depassivated metal surface (wear track) after removing the epoxy coating. The coated samples showed a potential drop of $200 \mathrm{mV}$ more negative potential than the non-coated samples showing the influence of the experimental conditions on the obtained electrochemical data in tribocorrosion experiments. Despite its usefulness, this experimental setup still lacked the possibility of measuring the current generated within the wear track.

Therefore in an attempt to improve the experimental methodology started in 2009 in the present work, a new experimental setup is proposed to measure the potential and the anodic current density only inside the wear track of a stainless steel alloy. Furthermore, the galvanic current flowing from the active wear track and the galvanic potential will be measured here with the use of a customized triboelectrochemical cell set-up in order to apply the ZRA technique to the tribosystem in a useful manner. The goal of these measurements is to quantify the wearaccelerated corrosion under equilibrium conditions, which should contribute to a better understanding of the underlying mechanisms in tribocorrosion OCP situations.

\section{Experimental procedure}

\subsection{Materials}

$25 \% \mathrm{Cr}$ super duplex stainless steel (UNS S32750) has been chosen as the passive metal alloy for investigation. The chemical composition of the alloy is (in wt.\%): $24.0-26.0 \mathrm{Cr}, 6.0-8.0 \mathrm{Ni}, 3.0-$ $5.0 \mathrm{Mo}, 0.24-0.32 \mathrm{Ti}, \mathrm{C} \leq 0.03, \mathrm{Mn} \leq 1.2, \mathrm{Si} \leq 0.8, \mathrm{Cu} \leq 0.5, \mathrm{P} \leq 0.035, \mathrm{~S} \leq 0.02$. The yield strength of the material is $568 \mathrm{MPa}$ [3].

The surface of the test samples was mirror polished to roughness values $\left(R_{a}\right)$ of $0.1 \mu \mathrm{m}$. All samples $(25 \times 25 \times 5 \mathrm{~mm})$ were cleaned in acetone in an ultrasonic bath prior to testing. In order to determine the potential only inside the wear track, some samples were coated with an organic electrically isolating material (epoxy based). The samples will be referred as uncoated and coated hereafter. 


\subsection{Polarization curves and potential measurements}

The corrosion resistance of the uncoated super duplex stainless steel alloy was evaluated by means of polarization measurements in aerated and unstirred $3.4 \mathrm{wt} . \% \mathrm{NaCl}$ solutions. For these experiments, a previously described electrochemical cell was used [18]. $\mathrm{An} \mathrm{Ag} / \mathrm{AgCl} / \mathrm{KClsat}$ electrode (SSC) was used as reference electrode. The counter electrode was a Platinum (Pt) wire. A working electrode of each sample was fixed at the bottom of the electrochemical cell, exposing an area of $0.78 \mathrm{~cm}^{2}$ to the solution. After the stabilization of the open circuit potential (OCP), the polarization curves were recorded using an Autolab PGSTAT 302N Potentiostat at a scan rate of 5 $\mathrm{mV} / \mathrm{min}$ in a potential range from -0.4 to $1.5 \mathrm{~V} \mathrm{vs}$. $\mathrm{Ag} / \mathrm{AgCl} / \mathrm{KCl}_{\text {sat }}$. Each measurement was carried out two times in order to check the repeatability of the experiments. All potentials in this paper are given with respect to the $\mathrm{Ag} / \mathrm{AgCl} / \mathrm{KCl}_{\text {sat }}$ reference electrode, referred here after as SSC.

The isolating properties of the epoxy-based coating were evaluated by means of open circuit potential measurements over time using an Autolab PGSTAT 302N Potentiostat.

From the polarization curves, several electrochemical parameters were extracted. The corrosion potential $\left(\mathrm{E}_{\text {corr }}\right)$, corrosion current density $\left(\mathrm{i}_{0}\right)$ calculated from the Tafel extrapolation through the Tafel constants and the corresponding anodic $\left(\beta_{\mathrm{a}}\right)$ and cathodic $\left(\beta_{\mathrm{c}}\right)$ Tafel slopes, parameters eventually used in the mathematical shortly introduced in section 3.2 [11].

\subsection{Tribocorrosion tests}

The tribocorrosion tests were carried out using a ball-on-flat reciprocating apparatus TriboCorr (Resmat Corporation, Canada) [19]. The machine performs electrochemical measurements on an immersed plate during the reciprocating motion of a counterpart. The counterpart used in this work was a $\mathrm{SiC}$ cylindrical pin of $1 \mathrm{~cm}$ diameter ground axisymmetricially to a conical tip of 90 degrees angle. The very end of the tip was microscopically rounded to a spherical finish with a diameter of $2.2 \mathrm{~mm}$ and the conical section of the pin geometry was found to commence at a pin width of 250-270 $\mu \mathrm{m}$ (blunt conical pin). In all cases the frequency of the sliding pin was $1 \mathrm{~Hz}$. One full revolution corresponded to $20 \mathrm{~mm}$ of sliding distance, equalling a linear speed of $72 \mathrm{~m} / \mathrm{h}$. The electrolyte used during the tests was $3.4 \mathrm{wt} . \% \mathrm{NaCl}$. The reference electrode used was $\mathrm{Ag} / \mathrm{AgCl} / \mathrm{KCl}_{\text {sat }}$ electrode (SSC) and the counter electrode was a Pt wire. Coated and uncoated samples were used, as described in Section 2.3.1 and loaded to 10 and $20 \mathrm{~N}$, corresponding to average Hertzian contact pressures of 768 and $967 \mathrm{MPa}$, respectively. The tests consisted of 3 steps: (1) measurement of the OCP during 10 min before rubbing, (2) rubbing during $30 \mathrm{~min}$ and (3) stop rubbing and measuring the OCP during $10 \mathrm{~min}$. During step 2, the OCP and coefficient of friction (COF) were recorded simultaneously. The tribometer has incorporated a potentiostat, however in order to measure the current flowing from the anode to the cathode, an external potentiostat (Autolab PGSTAT 302N) equipped with ZRA was connected. The samples were connected to the ZRA equipment to measure the current during rubbing at OCP as described in Section 2.4. Some rubbing cycles were used on the coated samples for removing the organic coating before the counterpart pin contacted the metal surface. The metal exposed area of the uncoated specimens to the electrolyte was either $5.6 \mathrm{~cm}^{2}$ or $2.8 \mathrm{~cm}^{2}$, whereas for the coated sample ZRA experiments the cathode surface area was always $2.8 \mathrm{~cm}^{2}$. All tests were performed at room temperature and two times for checking the repeatability. 


\subsubsection{Sample preparation for tribocorrosion tests}

The following steps were performed to prepare the samples for the ZRA experiments:

(1) The original samples (Figure 1a) were cut in two halves in order to get two new pieces of the same size. Afterwards, a piece of copper wire was welded to each piece of the sample (Figure 1b). After checking the electrical conductivity in each sample between the wire and the sample, the samples were embedded with resin: two pieces of metal per sample.

(2) The samples were ground down with SiC papers up to 2500 mesh and, afterwards, polished with 6, 3 and $1 \mu \mathrm{m}$ diamond suspension until mirror like finishing. Then, they were ultrasonically cleaned for 5 minutes in ethanol and, finally, dried using compressed air.

(3) One of the metal pieces was covered with the organic coating. This organic coating is epoxy based and it is prepared mixing two components. Once the two components are mixed, the surface of the sample is coated using a brush (Figure 1c). The organic coating has a thickness between 0.5 and $1 \mathrm{~mm}$, measured with a magnetic induction device.

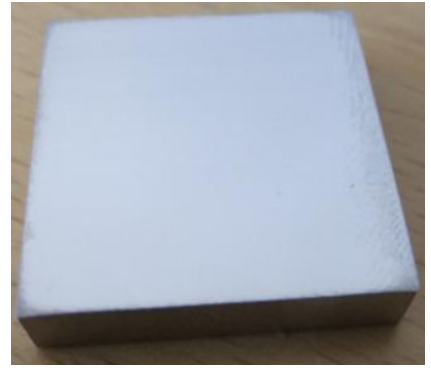

(a)

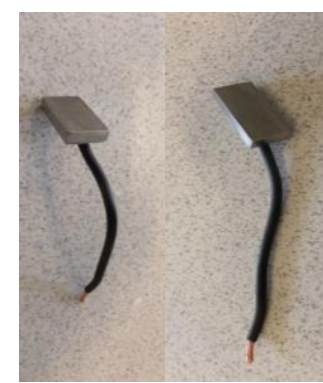

(b)

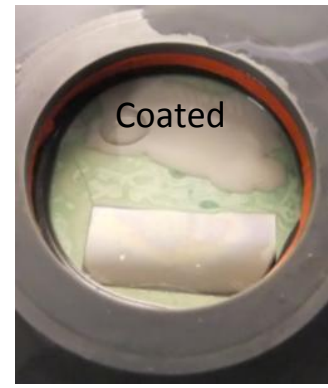

(c)

Figure 1. a) Original sample $(25 \times 25 \times 5 \mathrm{~mm})$, b) sample welded after cutting, c) samples ready for the test in the sample holder.

\subsection{Galvanic measurements}

In order to be able to measure the galvanic current between the depassivated and passivated areas of the sample during wear at OCP (tribocorrosion), zero-resistance ammetry (ZRA) technique was used. This non-invasive technique allows to measure quantitatively the current generated in a system with an accuracy in the order of nano Amperes (nA). Two working electrodes are necessary for performing the measurement. In this work the two electrodes were prepared as explained in section 2.3.1.

In Figure 2 electrode $A\left(W E_{A}\right)$ consists of the uncoated stainless steel sample (cathode) and electrode $B\left(W E_{B}\right)$ consists of the coated stainless steel sample (anode) exposed to the sliding action (according to section 2.3). The reference electrode (RE) was placed close to the two working electrodes as shown in Figure 2. The galvanic potential $\left(E_{G}\right)$ and the galvanic current $\left(I_{G}\right)$ were measured for the whole duration of the test using the ZRA configuration of an external potentiostat connected to the tribometer (see section 2.3).

It is worth noticing the effect of the uncoated sample area might have on the results. Since the wear track is generated in a separated sample, the cathode (non-coated sample, $W_{A}$ ) is not affected by the mechanical loading applied. In conventional tribocorrosion experiments this mechanical effect would mainly affect the surrounding edges of the worn area (i.e. plastic deformation induced by the normal load applied), which is not considered and observed in the 
present experimental set-up. The relevance of this effect can be considered negligible since it is expected to have this mechanical effect on the coated sample $\left(W E_{B}\right)$ when carrying out the ZRA experiments.

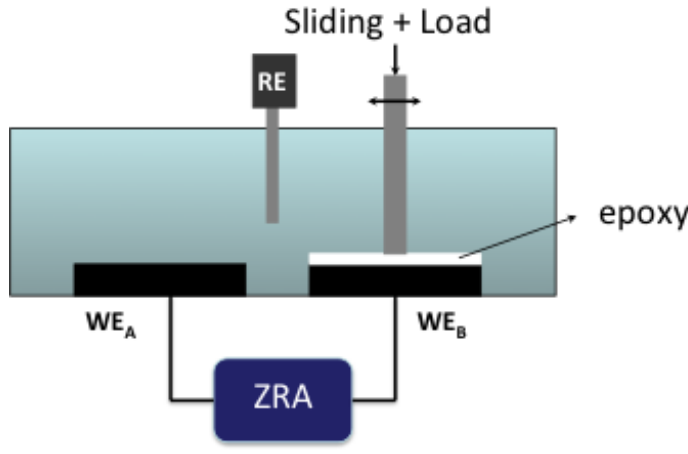

(a)

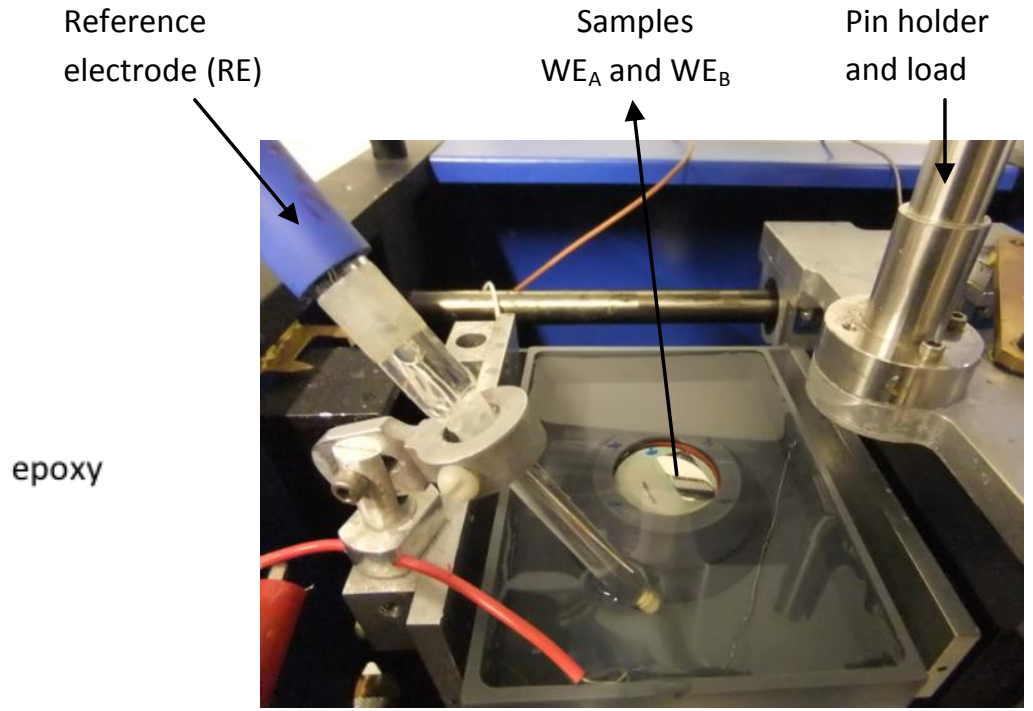

(b)

Figure 2. (a) Scheme of the electrochemical measurements carried out through a Zero-Resistance-Ammeter (ZRA) and (b) experimental set-up with the electrochemical cell and reference electrode position (the pin holder and load has been positioned in the opened position to allow for better view of the cell).

The ZRA technique has been used to measure both the galvanic potential $\left(E_{G}\right)$ the mixed potential established between the passive $\left(E_{c}\right)$ and depassivated areas $\left(E_{a}\right)$, as well as the anodic galvanic current only inside the wear track $\left(I_{G}\right)$. Figure 3 summarizes in an Evans diagram the different electrochemical parameters determined in this experimental work.

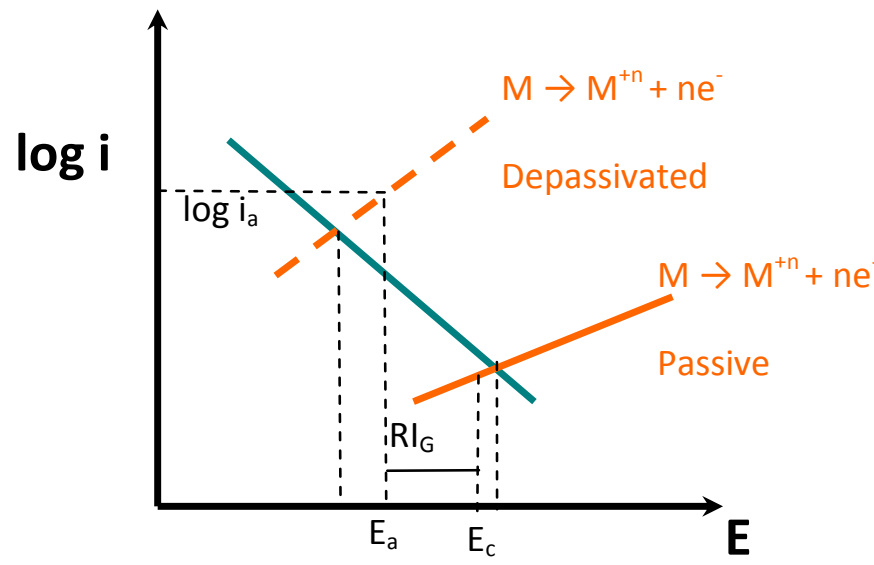

Figure 3. Evans diagram of the anode and the cathode of a tribocorrosion system at OCP sketching the position of the potential and current measured during the ZRA experiments. $R$ corresponds to all existing resistances between the anode and the cathode, thus $\mathrm{RI}_{\mathrm{G}}$ quantifies the ohmic drop occurring in the solution. 


\subsection{Volume loss and wear track analysis}

The volume loss was quantified by means of confocal microscopy (IFM Alicona, Austria) at the end of the tests. Cross sectional profiles were taken across the wear track for each sample. The width and depth of the wear track was measured from the wear track cross-section taken at three positions along the wear track and measured twice at each position. By multiplying these by the length of the track, the volume loss was then calculated.

The wear track topography was analysed by Scanning Electron Microscopy (SEM) Hitachi S-3400 N.

\section{Results and Discussion}

\subsection{Corrosion behaviour and polarization curves}

Figure 4 shows the polarization curves of the alloy in $3.4 \mathrm{wt} . \% \mathrm{NaCl}$. Four well-defined regions can be observed: the cathodic domain (potentials below the corrosion potential, $\mathrm{E}_{\text {corr }}$ ), the cathodicanodic transition at $E_{\text {corr }} \approx 0 \mathrm{~V}$, the passive plateau (between +0 and $+1 \mathrm{~V}$ ) and the transpassive dissolution. In the cathodic domain, no corrosion occurs and the current measured is negative due to the reduction of oxygen and water. During the cathodic-anodic transition the recorded current goes through zero at the corrosion potential $\left(E_{\text {corr }}\right)$. In the passive plateau the build up of a protective surface oxide film limits the current to a value lower to $2.5 \mu \mathrm{A} / \mathrm{cm}^{2}$. Finally in the transpassive domain the current density increases due to the oxidation of the film oxides and the oxygen evolution.

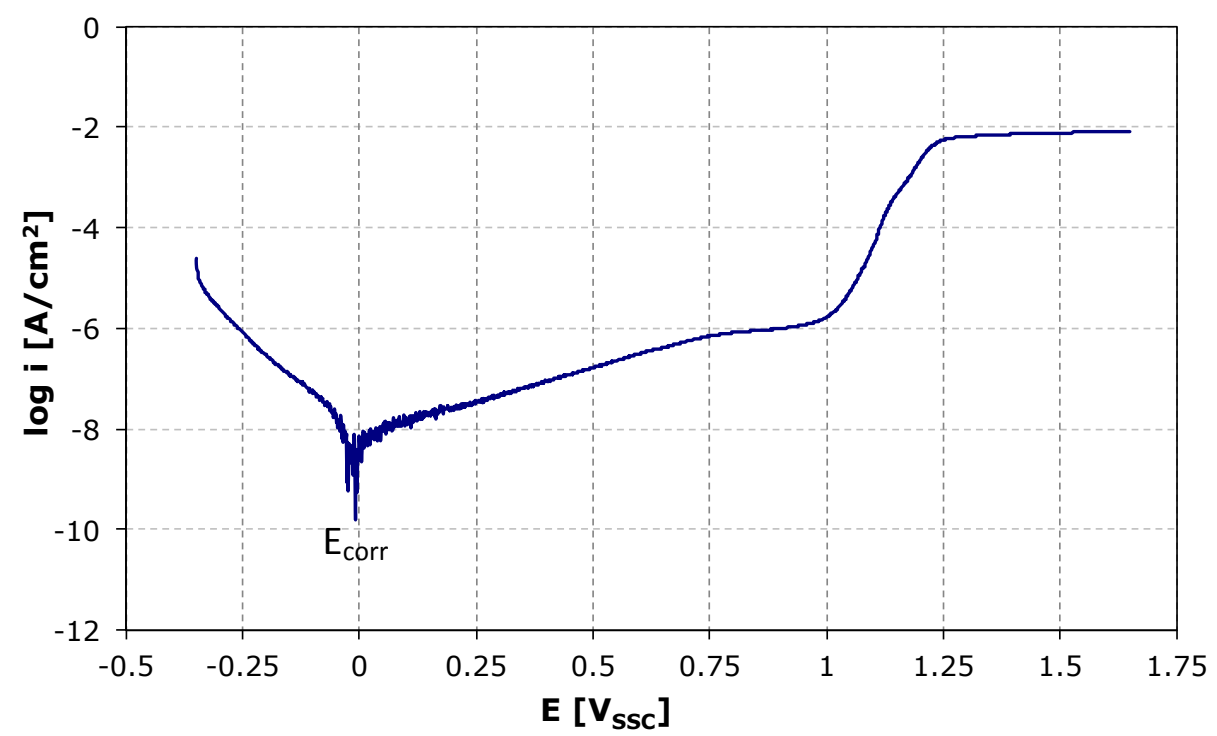

Figure 4. Polarization curve of the uncoated sample in $3.4 \mathrm{wt} . \% \mathrm{NaCl}$ at $5 \mathrm{mV} / \mathrm{min}$. Only one curve is shown since the repetition overlapped completely.

Figure 5 shows the potential evolution with time for the epoxy-coated super duplex stainless steel sample. It is clearly seen that the response of the sample cannot be measured due to the lack of electrical contact in the system. This is confirmed for all the time range in the measured open circuit potential. Indeed, in Figure 5 it can be seen how the recorded potential fluctuates between 
-3 and $3 \mathrm{~V}$ (potential limits of the potentiostat) during the whole test. Therefore, the epoxy coating acts as an effective barrier against electrolyte penetration.

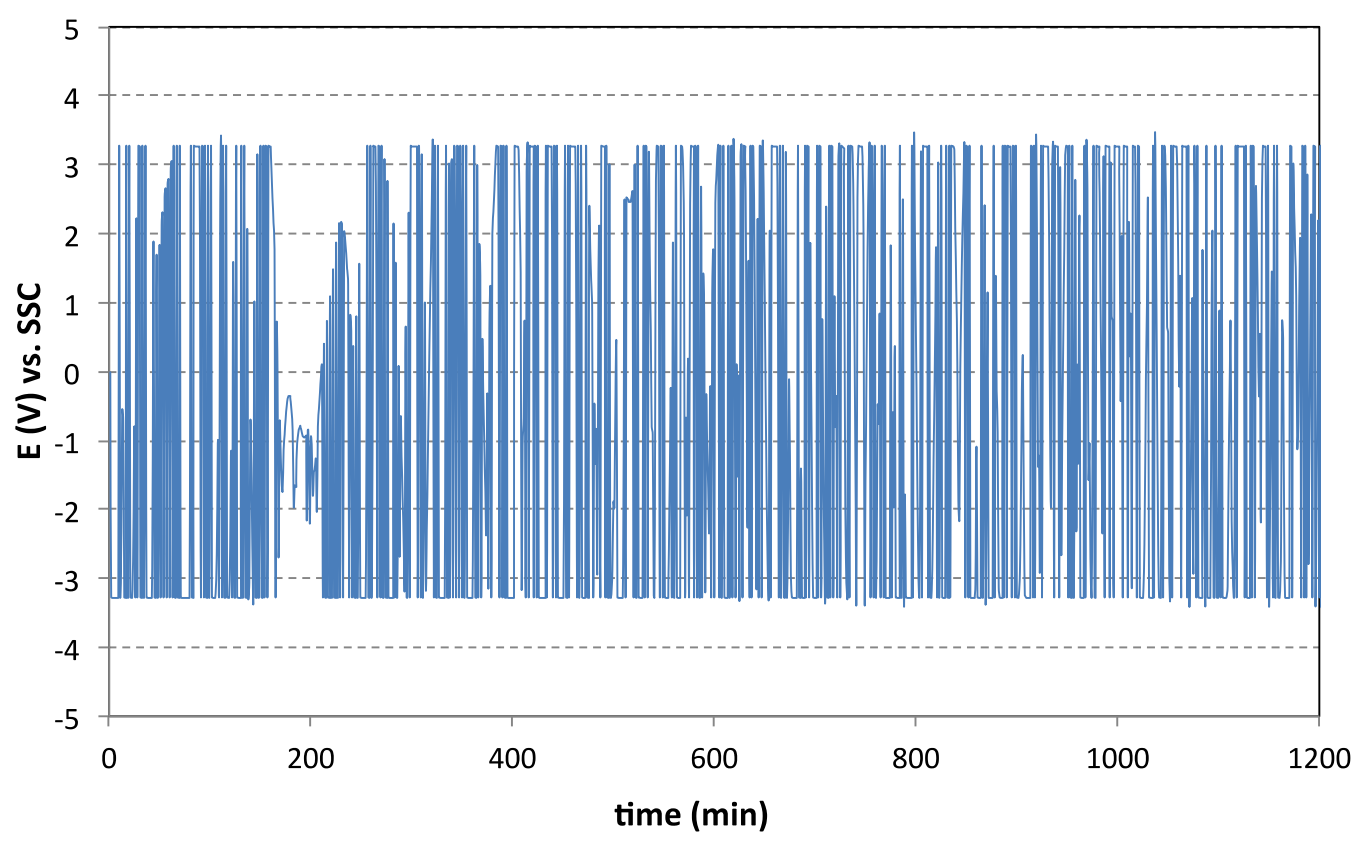

Figure 5. Potential evolution with time of the coated sample in $3.4 \mathrm{wt} . \% \mathrm{NaCl}$. Only one curve is shown since the repetition overlapped completely.

\subsection{Galvanic current and galvanic potential during tribocorrosion at OCP}

In this work, ZRA used in conjunction with an in-house designed electrochemical cell set-up enables performing tests using a cathode of the same material as the anode and measuring the necessary electrochemical parameters for measuring wear-accelerated corrosion under equilibrium conditions (see sections 2.3 and 2.4).

Figure 6 shows the experimental evolution of OCP with time (two repetitions shown) carried out by ZRA between a coated sample ( $W E_{B}$, rubbed sample) and a non-coated cathode (red lines), plotted against a conventional tribocorrosion OCP experiment (green line) where the anode (rubbed area) and the cathode (unrubbed area) are not physically separated. All the experiments plotted in figure 6 were performed with a cathode of $2.8 \mathrm{~cm}^{2}$ surface area. The average potential $\left(E_{G}\right)$ measured through the ZRA thus corresponds to the galvanic potential $E_{c}$ (Figure 3 ), which is equivalent to the OCP measured in the set-up during rubbing the anode and the cathode without any physical separation. Superposed is the result of a mathematical simulation curve (blue line) according to the galvanic coupling model for tribocorrosion at OCP [11]. This galvanic cell model for tribocorrosion at OCP determines the cathodic potential outside the wear track of a passive material using equation 1 [11].

$$
E_{c}=E_{c o r r}+a_{c}-b_{c} \log i_{a}-b_{c} \log \left(\frac{A_{a}}{A_{c}}\right)
$$

where $E_{c}$ is the cathodic potential outside the wear track (which is equal to the galvanic potential measured during tribocorrosion at $\mathrm{OCP}), \mathrm{a}_{\mathrm{c}}$ and $\mathrm{b}_{\mathrm{c}}$ are constants calculated from Tafel equations, $\mathrm{i}_{\mathrm{a}}$ 
is the anodic current density produced during the depassivation process inside the wear track and $A_{a}$ and $A_{c}$ are the surface areas of the anode and the cathode respectively.

As mentioned earlier, this model requires kinetic parameters such as the Tafel constants, which can be obtained from the polarization curves (Figure 4). In addition, the anodic current density and the anode and cathode areas are experimental parameters required for determining $E_{c}$, which until now had to be approximated in order to fit the experimental potential evolution during rubbing [11].

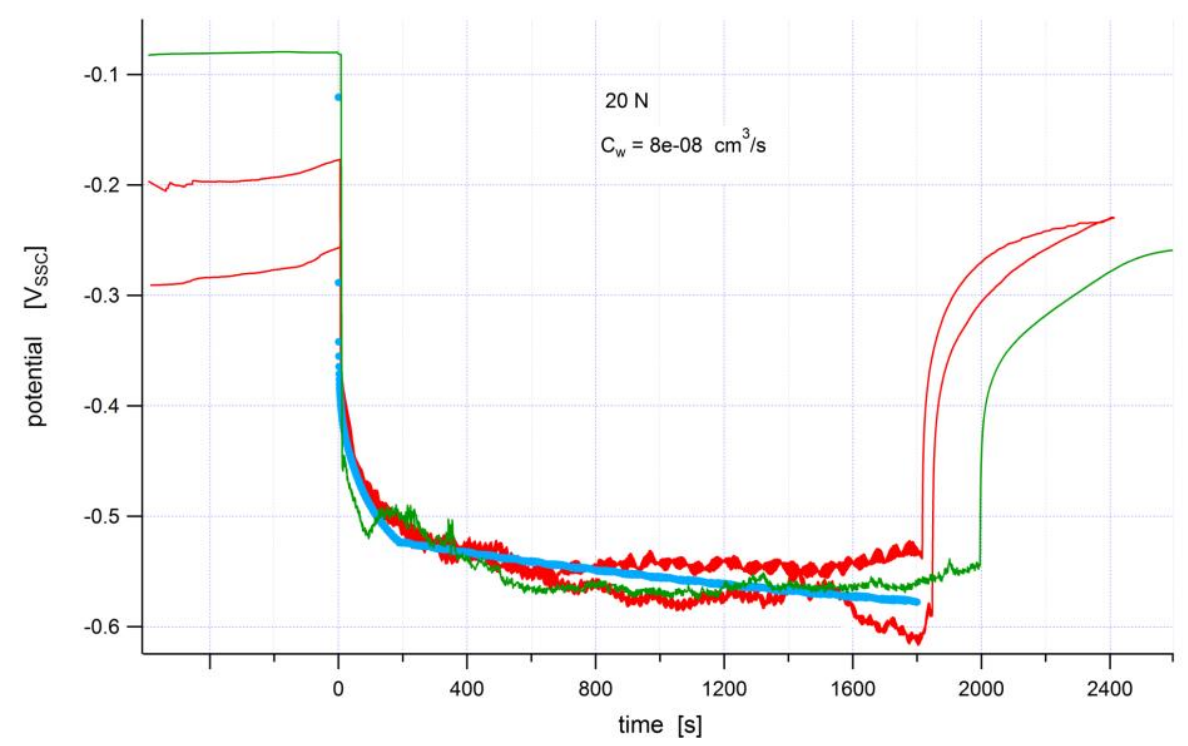

Figure 6. Experimental OCP curves for the SDSS sample in $3.4 \mathrm{wt} \% \mathrm{NaCl}$ and at $20 \mathrm{~N}$ load where one can distinguish: two repetitions of the ZRA experiment of a surface coated sample (red lines); a conventional tribocorrosion experiment at OCP (green line), and the superposed model OCP (mathematical simulation) curve (blue line).

The cathodic shift in the potential usually observed during tribocorrosion of passive metals at OCP can be explained by the galvanic coupling established between the mechanically depassivated areas (anode) and the surrounding passive areas (cathode). A galvanic ionic current flows from the anode (wear track) through the solution to the cathode, where electrons liberated at the anode by the metal oxidation and flowing through the metal are consumed by the reduction reaction. Considering the cathodic $\mathrm{i}_{\mathrm{c}}$ and anodic $\mathrm{i}_{\mathrm{a}}$ current densities (current per unit area), one can write for the case of tribocorrosion experiments [11]:

$i_{a} A_{a}=-i_{c} A_{c}$

where $A_{a}$ and $A_{c}$ correspond to the surface areas of the anode and the cathode, respectively. The relation between cathodic potential $E_{c}$ (identical to the recorded OCP) and the current density $i_{c}$ can usually be expressed by the linear part of the cathodic branch of the polarization curve (Tafel kinetics) as illustrated in equation (1).

According to equation (1), the cathodic potential $\left(E_{c}\right)$ in the galvanic coupling depends mainly on two factors: the anodic current and the anode-to-cathode area ratio. The mathematical modelling of the OCP evolution during reciprocating wear is therefore achieved by assuming that the wear track area $A_{w t}$ corresponds to the anodic area $A_{a}$, while the rest of the electrode surface (much larger area outside the wear track) constitutes the cathode area $A_{c}$. As a consequence of 
progressing wear, $A_{w t}$ increases with rubbing time. The wear track area $A_{w t}$ and the instantaneous wear track volume $\mathrm{V}$ are always related through geometrical conditions of the indentation of the pin into the sample [11].

An interesting feature of the curves plotted in Figure 6 is the similar OCP behaviour during rubbing of both coated and uncoated samples, as long as the cathode is similar, which in this case is a same material electrode of $2.8 \mathrm{~cm}^{2}$. This observation suggests that the coated sample tribocorrosion set-up and the conventional tribocorrosion experiment are equivalent. On the other hand, the galvanic coupling model predicts the OCP trend of the experiments [11]. However the model cannot predict the current flowing from the worn active area (anode) to the unworn passive area (cathode). Therefore, the ZRA set-up was used to record the anodic current during the tribocorrosion experiment. This anodic current is the galvanic coupling current flowing through the wear track.

The experimental galvanic current evolution with the number of cycles in a test performed at $20 \mathrm{~N}$ normal load is shown in Figure 7. The positive current values indicate that the electrons flow from the coated sample (rubbed electrode, only wear track). It is observed a large noise $(\sigma)$ on the current values $\left(\mathrm{I}_{\mathrm{G}}\right)$ during rubbing. This is due to the depassivation-repassivation processes taking place at the electrode surface of the anode. The average value of these fluctuations is considered to be equal to the galvanic current between the worn and unworn areas.

The data obtained from the ZRA experiments also allows for the calculation of a nominal average current density in the wear track experimentally. The increase in track surface area is reflected in the gradual upward trend of the total anodic current measured (Figure 7). The average anodic current density is estimated to be on the order of $3.1 \mathrm{~mA} / \mathrm{cm}^{2}$, when calculated from average internal wear track surface area and the total anodic current measured.

In order to confirm the experimental data obtained, the tribocorrosion galvanic model was applied using the $E_{c}$ values obtained in Figure 6 . The anodic current obtained from the model fitted the experimental data obtained with the ZRA (Figure 7), confirming the accuracy and usefulness of the experimental technique.

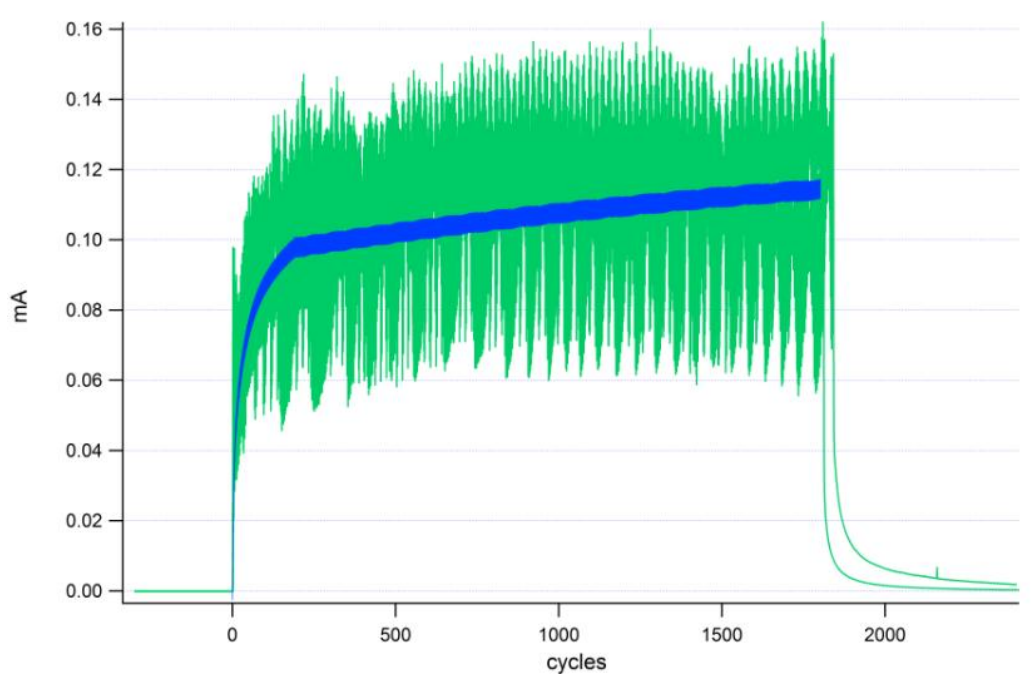

Figure 7. The experimental anodic current passing through the wear track as measured by the ZRA set-up (in green the two repetitions are plotted showing the good repeatability), under the same experimental conditions as described in figure 6 . The blue line shows the anodic current simulated mathematically. 
The cathode size is an important parameter in the galvanic coupling process [12] therefore to check the validity of the experimental set-up proposed in the present work, tests were performed surface area of $5.6 \mathrm{~cm}^{2}$, the rest of the parameters of the tribocorrosion experiment were kept equal to the tests performed with a surface area of $2.8 \mathrm{~cm}^{2}$.

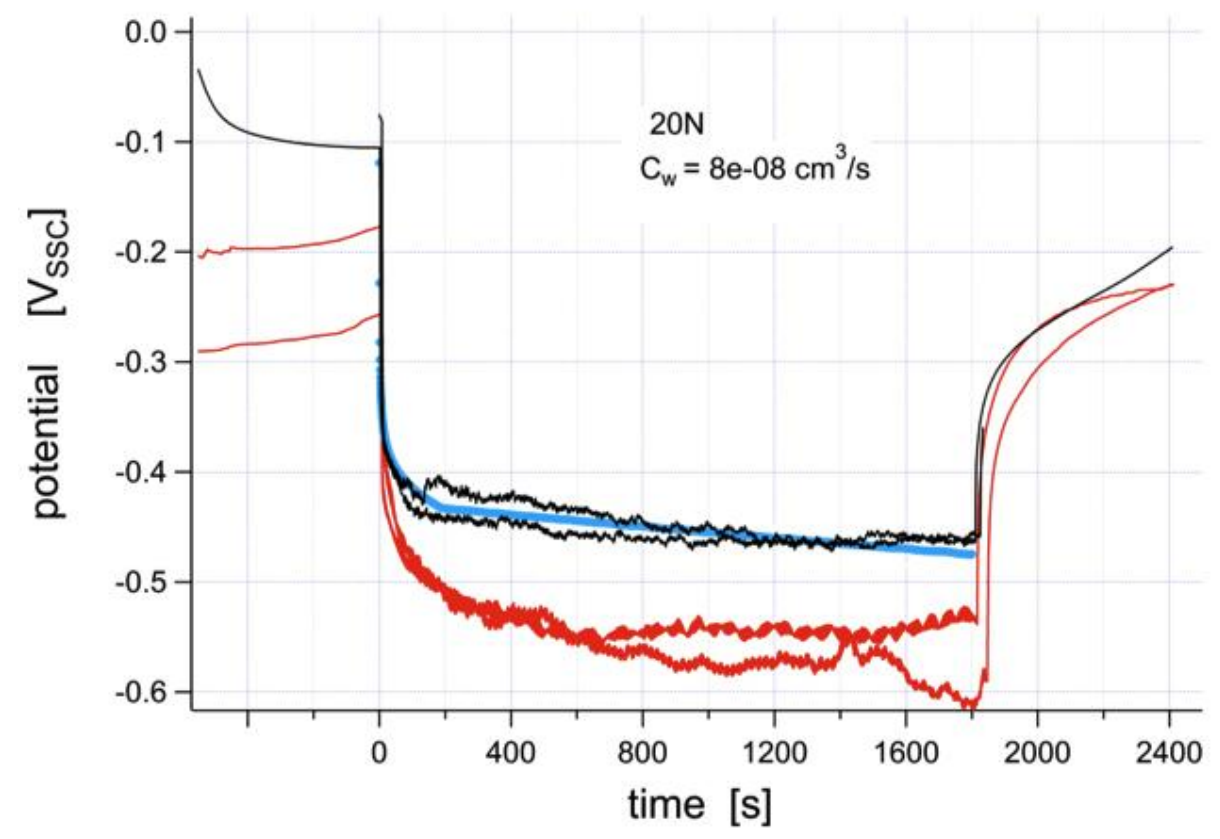

Figure 8. Experimental OCP curves produced under the conditions described in figure 6, showing two repetitions of the test with a cathode of $5.6 \mathrm{~cm}^{2}$ (black lines) along with the galvanic coupling mathematical simulation curve (blue line). For comparison, the experiments conducted with the cathode surface area of $2.8 \mathrm{~cm}^{2}$ are also included (red lines).

The OCP of the samples with double the surface area of the cathode moves towards more positive potential values as expected from the galvanic coupling principles taking into account the different size cathode utilized $[1,7]$. These results provide with a strong support to the ZRA experimental set-up for tribocorrosion purposes in equilibrium conditions. Therefore, the technique can be used not only for determining the wear-accelerated corrosion under equilibrium conditions but also for other purposes such as the quantification of the real depassivated area during tribocorrosion situations and elucidating wear mechanisms.

\subsection{Mechanical aspects in tribocorrosion galvanic coupling}

The results showed in the previous sections were concentrated on tribocorrosion conditions at 20 $\mathrm{N}$ normal load. Experiments at $10 \mathrm{~N}$ were also performed using the ZRA set-up to study the effect of the mechanical loading on the tribocorrosion galvanic coupling mechanism. The evolution of the OCP and the evolution of the anodic current during rubbing at OCP at $10 \mathrm{~N}$ normal load showed a different behaviour with respect to the higher load test (Figure 9). There is a trend towards more positive potentials in the OCP responses and a downtrend in the anodic current during rubbing at $10 \mathrm{~N}$, both indicate that the behaviour of the material at $10 \mathrm{~N}$ is different than in the $20 \mathrm{~N}$ case. 
Table 1 summarizes the main parameters (the potential, the anodic current and the volume loss) after tribocorrosion testing at $\mathrm{OCP}$ at 10 and $20 \mathrm{~N}$ with the new tribocorrosion set-up proposed in this work. As mentioned earlier, the measurement of the anodic current during rubbing at OCP allows for the quantification of the wear-accelerated corrosion. Therefore applying Faraday's law (equation 3 ) and the mechanistic approach for tribocorrosion (equation 4) one can quantitatively determine the chemical and mechanical contributions to material loss during tribocorrosion at OCP for the first time [5].

$$
\begin{array}{r}
V_{\text {chem }}=\frac{I t M}{n F} \\
V_{\text {total }}=V_{\text {mech }}+V_{\text {chem }}
\end{array}
$$

where $V_{\text {chem }}$ is the volume loss due to the metal oxidation during time $t, V_{\text {total }}$ is the total material loss in the wear track (equal to $V_{w t}$ ), $V_{\text {mech }}$ is the mechanical volume loss (calculated as the difference between $V_{\text {total }}$ and $V_{\text {chem }}$ ), $I$ is the anodic current, $F$ is the Faraday's constant (approximately $96500 \mathrm{c} / \mathrm{mol}$ ), $\mathrm{n}$ is the oxidation valence of the metal, $\mathrm{M}$ is the atomic mass of the metal and a is the density of the metal.

Table 1. Volume loss measurements (total, chemical and mechanical), $E_{c}$ and $I_{a}$ during tribocorrosion at OCP using the ZRA test set-up. For all samples the stroke length was $10 \mathrm{~mm}$. Two repetitions of the same tests are shown in the

\begin{tabular}{|c|c|c|c|c|c|c|c|c|c|c|}
\hline \multirow{2}{*}{ Sample } & \multicolumn{2}{|c|}{$E_{c}(V)$} & \multicolumn{2}{|c|}{$I_{a}(m A)$} & \multicolumn{2}{|c|}{$\begin{array}{c}V_{\text {total }} \\
\left(\mathrm{mm}^{3}\right)\end{array}$} & \multicolumn{2}{|c|}{$\begin{array}{l}V_{\text {chem }} \\
\left(\mathrm{mm}^{3}\right)\end{array}$} & \multicolumn{2}{|c|}{$\begin{array}{l}V_{\text {mech }} \\
\left(\mathrm{mm}^{3}\right)\end{array}$} \\
\hline & $10 \mathrm{~N}$ & $20 N$ & $10 \mathrm{~N}$ & $20 \mathrm{~N}$ & $10 \mathrm{~N}$ & $20 \mathrm{~N}$ & $10 \mathrm{~N}$ & $20 N$ & $10 \mathrm{~N}$ & $20 \mathrm{~N}$ \\
\hline \multirow{2}{*}{ Coated } & -0.507 & -0.538 & 0.084 & 0.100 & 0.051 & 0.138 & 0.0044 & 0.0052 & 0.047 & 0.133 \\
\hline & -0.458 & -0.558 & 0.073 & 0.113 & 0.045 & 0.220 & 0.0038 & 0.0059 & 0.041 & 0.214 \\
\hline \multirow{2}{*}{$\begin{array}{c}\text { Un- } \\
\text { coated }\end{array}$} & $\begin{array}{c}-0.398 \\
\end{array}$ & -0.455 & - & - & 0.040 & 0.093 & - & - & - & - \\
\hline & -0.439 & -0.439 & - & - & 0.071 & 0.129 & - & - & - & - \\
\hline
\end{tabular}
table.

This different behaviour depending on the load applied can be the result of two different effects, the electrochemistry of the system and the mechanical aspects. For the former, a different depassivation and repassivation phenomena of the sample at $10 \mathrm{~N}$ normal load is expected. This is due to the lower contact pressure within the contact at the different loads (768 and $967 \mathrm{MPa}$ at 10 and $20 \mathrm{~N}$, respectively) that modifies the triboelectrochemical response of the samples. Indeed, one could expect less plastic deformation in the tests performed at $10 \mathrm{~N}$. As can be seen in Figure 10, the wear track topography of the coated samples tested at $10 \mathrm{~N}$ shows a much more abrasive behaviour (2-body abrasion, Figure 10a), while the one at $20 \mathrm{~N}$ shows an abrasive behaviour with a larger degree of plastic deformation (Figure 10b). This different mechanical behaviour will have also an influence on the depassivation of the material, which could actually decrease as the test advances as a consequence of a decrease in the contact pressure due to the larger area of contact. Therefore at $10 \mathrm{~N}$ normal load, the current and potential evolution with time decreases and increases respectively (Figure 9). This different response in potential and current evolution is indeed confirmed by the mechanical material removed $\left(V_{\text {mech }}\right)$ in the coated samples. Table 1 shows the largest mechanical wear (almost one order of magnitude higher) at $20 \mathrm{~N}$ while similar chemical volume is observed at the two loads applied. Therefore, the triboelectrochemical response of the samples at $10 \mathrm{~N}$ is different than expected from the galvanic coupling model since 
the model is not able to take into account the mechanical aspects of wear in tribocorrosion. However, the experimental technique presented in this work is able to monitor both, the mechanical and electrochemical changes in the contact. Indeed the tests performed at $10 \mathrm{~N}$ actually show less material removal, therefore lower anodic current and potential is expected and actually obtained (Table 1 and Figure 9 respectively).



(a)

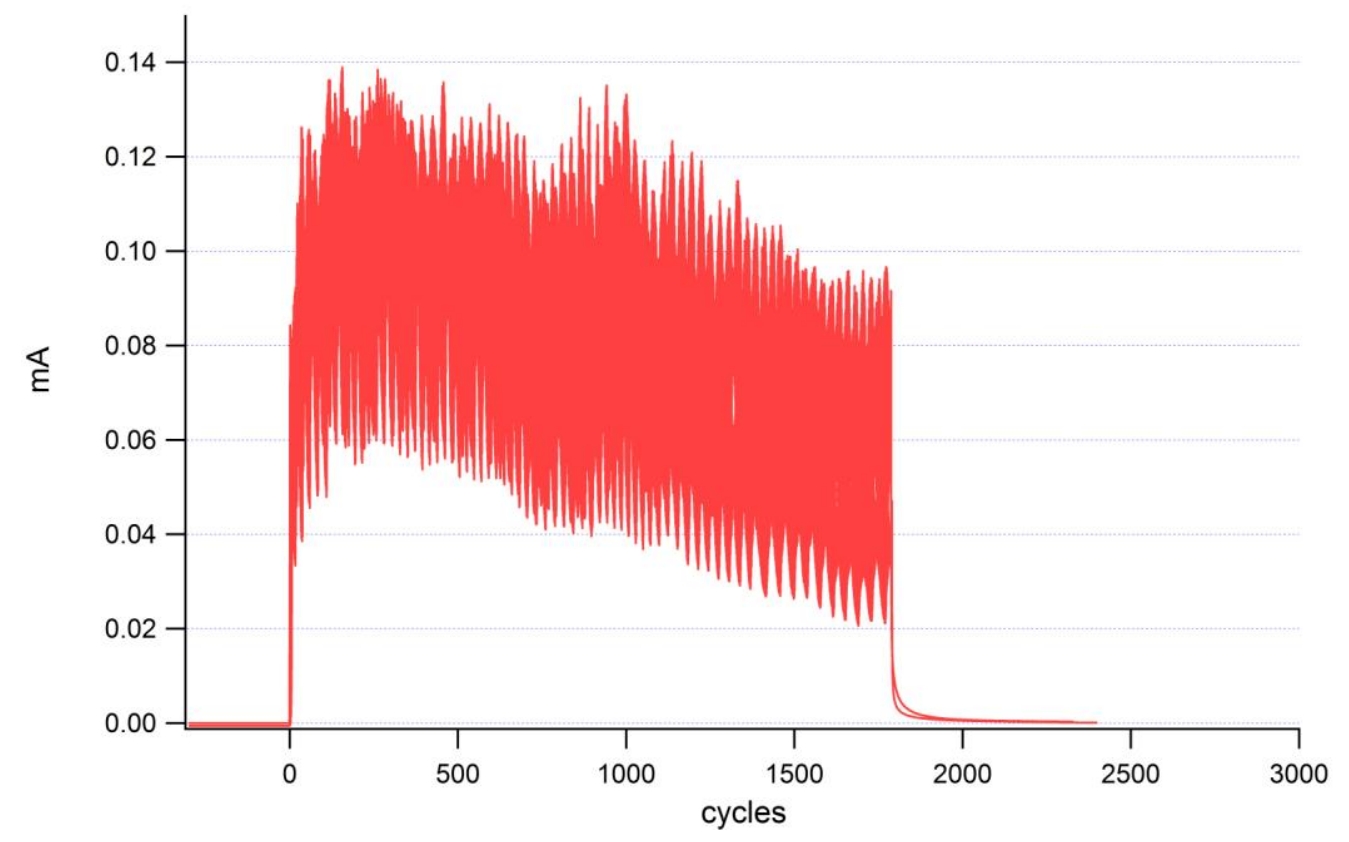

(b)

Figure 9. Two repetitions of the tribocorrosion experiment of a coated sample: (a) OCP evolution during rubbing and (b) the evolution during rubbing of the anodic current passing through the wear track, produced under $10 \mathrm{~N}$ load, the other conditions being equal to those described in figure 6 . Both experiments have cathode surface area of $2.8 \mathrm{~cm}^{2}$. 


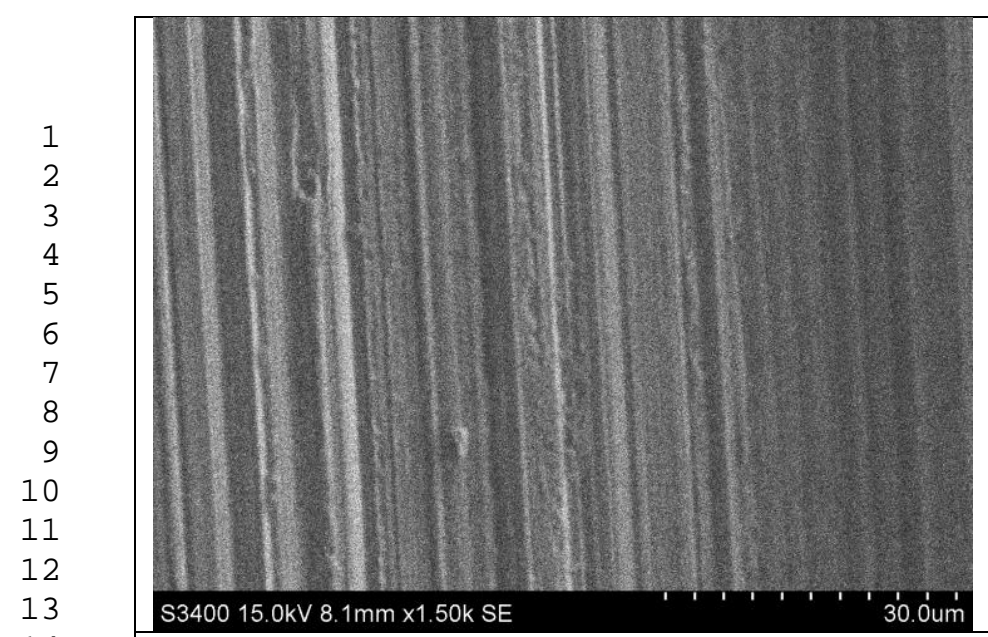

(a)

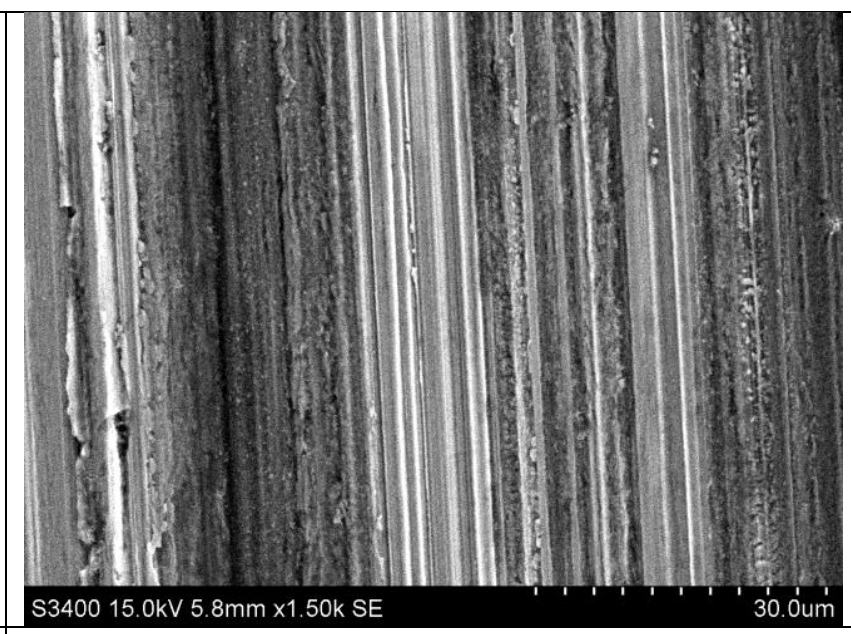

(b)

Figure 10. SEM images of the wear track topography of the coated samples after tribocorrosion testing at (a) $10 \mathrm{~N}$ and (b) $20 \mathrm{~N}$.

\section{Conclusions}

This work was initiated with the aim of experimentally determining the galvanic coupling between the worn and unworn areas existing in a tribocorrosion test setup at OCP for passive materials using a stainless steel. The following conclusions can be drawn:

- A new tribocorrosion cell setup for simulating the galvanic coupling between worn and unworn areas has been built-up by physically isolating the anode and the cathode (worn and unworn areas) of a sample subjected to rubbing and electrically connecting them via a zero-resistance ammeter (ZRA).

- The use of the ZRA technique and the physical separation of the anode (worn area) and the cathode (unworn area) by using an epoxy coating on the stainless steel sample allowed for the determination of the galvanic potential and anodic current inside the wear track during tribocorrosion at open circuit potential (OCP).

- This new experimental setup can be used as a quantitative tool for determining the galvanic coupling parameters during tribocorrosion at OCP and also for determining the wear-accelerated corrosion at OCP.

- $\quad$ The experimental tool presented in this work may constitute the experimental basis for further developing tribocorrosion models that can include not only the electrochemical aspects, but also the mechanical ones during tribocorrosion.

\section{Acknowledgements}

The authors would like to thank the support from the European Union for funding $\mathrm{C}$. Torres through the Leonardo da Vinci Mobility program. Dr. N. Papageorgiou (NTNU) is also acknowledged for the input and calculations in the modelling part. 


\section{References}

[1] D. Landolt. Corrosion and surface chemistry of metals. Lausanne; EPFL Press; 2007.

[2] A. Igual-Munoz and S. Mischler, Effect of the environment on wear ranking and corrosion of biomedical CoCrMo alloys, J. Mater. Sci. Mater. Med. 22(3), 437-450 (2011).

[3] C.B. von der Ohe, R. Johnsen, N. Espallargas, Multi-degradation behavior of austenitic and super duplex stainless steel - The effect of 4-point static and cyclic bending applied to a simulated seawater tribocorrosion system, Wear 288 (2012) 39-53.

[4] S. Mischler, Triboelectrochemical techniques and interpretation methods in tribocorrosion: A comparative evaluation, Tribology International 41 (2008) 573-583.

[5] A.I. Munoz and N. Espallargas. Tribocorrosion mechanisms in sliding contacts, in: D.Landolt, S.Mischler (Eds.), Tribocorrosion of Passive Metals and Coatings Woodhead Publishing, Lausanne, 2011.

[6] Sandra Guadalupe Maldonado, Stefano Mischler, Marco Cantoni, Walter-John Chitty, Carole Falcand, Dominique Hertz, Mechanical and chemical mechanisms in the tribocorrosion of a Stellite type alloy, Wear, Available online 25 April 2013, http://dx.doi.org/10.1016/i.wear.2013.04.007.

[7] N.S. More, N. Diomidis, S.N. Paul, M. Roy, S. Mischler, Tribocorrosion behavior of $\beta$ titanium alloys in physiological solutions containing synovial components, Materials Science and Engineering: $C$ 31(2) (2011) 400-408.

[8] E. Bardal. Corrosion and protection. Springer London (2004). ISBN: 978-1-85233-758-2.

[9] P. Ponthiaux, F. Wenger, D. Drees, J.P. Celis, Electrochemical techniques for studying tribocorrosion processes, Wear 256 (2004) 459-468.

[10] Y. Sun, Vipul Rana, Tribocorrosion behaviour of AISI 304 stainless steel in $0.5 \mathrm{M} \mathrm{NaCl}$ solution, Materials Chemistry and Physics 129(1-2) (2011) 138-147.

[11] A.C. Vieira, L.A. Rocha, N. Papageorgiou and S. Mischler, Mechanical and electrochemical deterioration mechanisms in the tribocorrosion of $\mathrm{Al}$ alloys in $\mathrm{NaCl}$ and in $\mathrm{NaNO}_{3}$ solutions, Corrosion Science 54 (2012) 26-35.

[12] M. Azzi and J.E. Klemberg-Sapieha. Tribocorrosion test protocols for sliding contacts, in: D.Landolt, S.Mischler (Eds.), Tribocorrosion of Passive Metals and Coatings Woodhead Publishing, Lausanne, 2011.

[13] F. Galliano, E. Galvanetto, S. Mischler, D. Landolt, Tribocorrosion behavior of plasma nitrided Ti$6 \mathrm{Al}-4 \mathrm{~V}$ alloy in neutral $\mathrm{NaCl}$ solution, Surface and Coatings Technology 145(1-3) (2001) 121-131.

[14] Pei-Qiang $\mathrm{Wu}$, J.-P Celis, Electrochemical noise measurements on stainless steel during corrosionwear in sliding, Wear 256(5) (2004) 480-490.

[15] E. Jensen, N. Espallargas, R. Johnsen, C.B. von der Ohe, Tribocorrosion properties of super duplex stainless steel in $3.4 \% \mathrm{NaCl}$ and $\mathrm{H}_{2} \mathrm{SO}_{4} 0.5 \mathrm{M}$ solutions. Article 8083 in proceedings of EUROCORR 2009, Nice, France.

[16] A. Berradja, F. Bratu, L. Benea, G. Willems, J.-P. Celis, Effect of sliding wear on tribocorrosion behaviour of stainless steels in a Ringer's solution, Wear 261(9) (2006) 987-993. 
[17] A. Berradja, D. Deforge, R.P. Nogueira, P. Ponthiaux, F. Wenger, J.P. Celis, An electrochemical noise

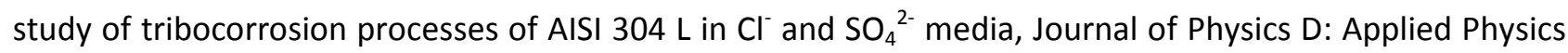
39 (2006) 3184-3192.

[18] P.H.Suegama, C.S.Fugivara, A.V.Benedetti, J.Fernández, N.Espallargas, J.Delgado, J.M.Guilemany In: E.P. Vargus, Editor, New Researches on Electrochemistry, Chapter 4: Microstructure and electrochemical studies of $\mathrm{Cr}_{3} \mathrm{C}_{2}-\mathrm{NiCr}$ coatings obtained by HVOF, Nova Science Publishers, Inc., N.Y. (2007), p. 113.

[19] M. Azzi, J.A. Szpunar, Tribo-electrochemical technique for studying tribocorrosion behavior of biomaterials, Biomolecular Engineering 24 (2007) 443-446. 